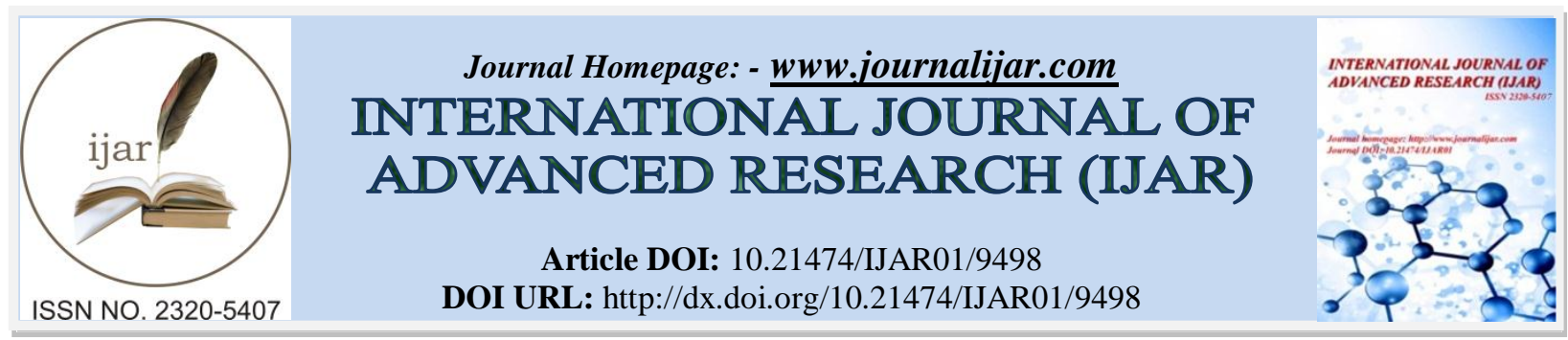

RESEARCH ARTICLE

\title{
EFFECT OF CAFFEINATED DRINK ON LIPID PROFILE IN ALLOXAN-INDUCED DIABETIC MALE ALBINO RATS.
}

\author{
Akinola, F. F ${ }^{1}$, Ogundiran, S. $\mathbf{M}^{2}$, Oladapo A. A ${ }^{3}$ and Busari, A. $\mathrm{O}^{4}$. \\ 1. Department of biomedical sciences, Ladoke Akintola University of Technology, Ogbomosho, Nigeria. \\ 2. Coffey County Hospital, Burlington, Kansas 66839 USA. \\ 3. William Newton Memorial Hospital, Winfield, Kansas 67156 USA.
}

\section{Manuscript Info}

\section{Manuscript History}

Received: 05 June 2019

Final Accepted: 07 July 2019

Published: August 2019

Key words:-

Diabetes mellitus, caffeinated drink,

HDL-C, Triglyceride, LDL-C, Total Cholesterol.

\begin{abstract}
Alteration of glucose metabolism has been shown to cause variation in the lipid profile. This study assesses the effects of caffeinated drink on lipid profile in the alloxan-induced diabetic male rat. We divided fifty male albino rats into five groups, Negative control, Positive (diabetes) control, and three experimental groups. The negative and positive controls were fed with standard rat chow with water, and the 3 test groups were fed with standard rat chow with water, and a relative percentage of caffeinated drink for two weeks. After two weeks of the experiments, the animals were sacrificed, and blood samples were collected, and laboratory investigations of serum lipid profile were carried out using the standard spectrophotometric method. Our result shows a significant increase $(\mathrm{p}<0.05)$ in serum total- cholesterol (TC), Triglycerides (TG) and LDL-C but a significant decrease $(\mathrm{p}<0.05)$ in serum HDL-C in the positive control group compared to the negative control. However, there was a noteworthy increase in Triglycerides (TG) and LDL-C in group $3 \& 4$ compared to the negative control. Also, there was a remarkable increase $(p<0.05)$ in serum HDL-C level in group 5 compared to negative control groups, while TC, TG \& LDL$\mathrm{C}$ serum level of group 5 are in equilibrium with the negative control group. Therefore, caffeinated drink can be said to have anti-lipidemic effect in the alloxan-induced diabetic male rats.
\end{abstract}

Copy Right, IJAR, 2019,. All rights reserved.

\section{Introduction:-}

Diabetes mellitus is a complex metabolic disorder caused by disruption of insulin signaling pathways, and the defects usually result from pancreatic $\beta$-cell deficiency / and a deficiency of insulin (Kahn, 1994). Hyperglycemia, the major clinical manifestation of diabetes, is thought to contribute to diabetic complications by altering vascular cellular metabolism, vascular matrix molecules, and circulatory lipoproteins, (Chattopadhy and Bandyopadhyay, 2005). Diabetes mellitus is known to be associated with lipid metabolism abnormalities (Odetola et al., 2006).

Hyperlipidemia is one of the metabolic complications of both clinical and experimental diabetes mellitus (Gandhi, 2001; Szkudelshi, 2001). Altered lipids and lipoprotein metabolism in chronic diabetes mellitus is associated with the pathogenesis of atherosclerosis and other cardiovascular diseases (Manninen et al., 1992). Abnormalities in plasma lipids and lipoprotein patterns due to defect in insulin insufficiency have been reported in diabetes mellitus

Corresponding Author:- Akinola, F. F.

Address:- Department of biomedical sciences, Ladoke Akintola University of Technology, Ogbomosho, Nigeria. 
(Das and Mohan, 2003). Low-density lipoprotein in diabetic patient lead to abnormal metabolism and is associated with increased Very Low - Density Lipoprotein (VLDL) secretion and impaired VLDL catabolism (Howard, 1987). Ultimately this leads to atherosclerotic plaque and several known factors of coronary heart disease such as high blood pressure, obesity, and dyslipidemia are more common in people with diabetes than in the general population (Howard, 1987).

Dyslipidemia is a frequent complication of diabetes mellitus and is characterized by low levels of high-density lipoprotein-cholesterol (HDLC) and high levels of low-density lipoprotein cholesterol (LDLC) and triglycerides (TG) (Howard, 1987).

Caffeine is an ergogenic substance widely consumed in drugs, and beverages, such as coffee and energy drink. Consumption of caffeine in beverages is notably rampant in the society, specifically, in the sport, for performance enhancement (Graham 2001). A plethora number of researches have shown that caffeine increases mental capability, increases strength and endurance (Graham, 2001; Davis and Green 2009).

Recently, a lot of researches have been done on caffeine, and these have resulted in a surge of publications dealing with a variety of pharmaco-physiological effects of caffeine. In this present study, we examined the impact of caffeinated drink in alloxan-induced diabetic male albino rats. We hypothesized that caffeinated drinks will restore serum lipid profile to near normal in alloxan-induced diabetic rat.

\section{Materials and methods:- Experimental animals}

We used healthy Male albino rats of Wistar strain for this experimental study; Female albino rats were excluded to avoid the interference of reproductive hormones on the biochemical parameters being measured while the experiment lasted. Fifty healthy male albino rats of at least 8 weeks old, weighing between $140 \mathrm{~g}-159 \mathrm{~g}$ were obtained from the animal house of Ladoke Akintola University of Technology, housed in a well-constructed cage and allowed to adapt for 7 days. The animals were placed in a well-ventilated cage made with wood and wire mesh under the controlled environmental condition of 12 hours light/day circle, temperature between 21 -31 degree Celsius and relative humidity between 45\%-55\%. All animals were made to receive humane care following the principle of laboratory animals care of the National Society of Medical Research (National Institutes of Health Publications no. 80-23, revised 1978) and approved by Ladoke Akintola University of Technology College of health sciences ethics committee.

\section{Experimentaldrink}

Caffeinated drink- 32 fl.oz (946ml)- containing 302.6mg caffeine.

Using distilled water as a diluent, $25 \%, 50 \%$, and $100 \%$ of caffeinated drink- 32 fl. oz (946ml) was prepared daily according to the table I below:

\begin{tabular}{|l|l|l|}
\hline Concentration & Volume of diluent & Volume of caffeinated drink \\
\hline $25 \%$ & $75 \%$ & $25 \%$ of Caffeinated drink- 32 fl. oz (946ml) \\
\hline $50 \%$ & $50 \%$ & $50 \%$ of Caffeinated drink- $32 \mathrm{fl.} \mathrm{oz}(946 \mathrm{ml})$ \\
\hline $100 \%$ & Nil & $100 \%$ of Caffeinated drink- $32 \mathrm{fl.} \mathrm{oz}(946 \mathrm{ml})$ \\
\hline
\end{tabular}

Table I: Preparation of different concentration of caffeinated drinks

\section{Experimental Design}

Fifty healthy male albino rats were divided into 5 groups; all the experiments were carried out within two weeks. The different groups were classified as described in Table 2.

\section{Induction Of Diabetes In Experimental Animals}

Diabetes mellitus in the experimental animals was induced by a single dose of intraperitoneal injection of freshly prepared solution of alloxan monohydrate $(160 \mathrm{mg} / \mathrm{kg})$ dissolved in physiological saline in overnight fasted albino rats (Sigma-Aldrich, Inc., St. Louis, MO 63103 USA). The diabetes was assessed in alloxan-induced rats by determining the blood glucose concentration 48 hours after injection of alloxan. The blood sample was obtained from the tail vein of the animals, to determine the fasting blood glucose level with the use of a digital glucometer (Accu-chek® Active, Roche Diagnostic, Germany). The animals fasted for a time of 16 hours before their blood 
glucose level was measured. The rats with blood glucose level above $14.43 \mathrm{mmol} / \mathrm{L}$ were selected for the experimental study.

\section{Experimental Procedure}

Table II below shows the grouping of animals. All the animal groups have access to rat diets, water, and the relative percentage of caffeinated drink, respectively.

\begin{tabular}{|l|l|l|l|l|}
\hline Groups & Species & Gender & Treatment & $\begin{array}{l}\text { Total number } \\
\text { of }\end{array}$ \\
\hline 1 & RATS & MALE & Healthy rats without DM+ Rat diet + water & 10 \\
\hline 2 & RATS & MALE & Induced diabetic rats + Rat diet+water & 10 \\
\hline 3 & RATS & MALE & $\begin{array}{l}\text { Induced diabetic rats + Rat diet + water }+25 \% \\
\text {-affeinated drink }\end{array}$ & 10 \\
\hline 4 & RATS & MALE & $\begin{array}{l}\text { Induced diabetic rats + Rat diet + water +50\% } \\
\text {-affeinated drink }\end{array}$ & 10 \\
\hline 5 & RATS & MALE & $\begin{array}{l}\text { Induced diabetic rats + Rat diet + water }+100 \% \\
\text { faffeinated drink }\end{array}$ & 10 \\
\hline
\end{tabular}

TABLE II: Animal groups with respective treatments.

\section{Sample Collection And Storage}

After two weeks of treatments, animals were fasted overnight but had free access to water. Animals were anesthetized using chloroform. Between 2-3mls of whole blood was collected through heart puncture into the plain bottles, after clotting occurred then it was centrifuged at $3000 \mathrm{~g}$ for $10 \mathrm{~min}$, and the supernatant was collected into plain tubes for analysis.

\section{Biochemical Analysis Of Lipid Profile}

The serum lipid profile specifically, Total cholesterol (TC), High-Density lipoprotein cholesterol (HDL-C), Triglyceride (TG), and Low-Density Lipoprotein cholesterol (LDL) were analyzed in the Laboratory using Lipid profile kits method and following the manufacturer's procedures (obtained from Heymed Supply, Washington D.C USA).

\section{Animal Weight Measurements}

Rat body weights were measured at the start of the experimental period, after two weeks, using a digital balance (VWR® P-Series Portable Balances, Model: VWR-500P).

\section{Data And Statistical Analysis:}

The experimental data were analyzed using the Statistical Package for Social Sciences (SPSS). All experimental data were expressed as mean \pm standard error of the mean (SEM). The statistical analysis was done by one-way analysis of variance (ANOVA). The level of significance was taken at $\mathrm{P}<0.05$.

\section{Results:-}

\section{Body Weight Changes}

Rat body weights were measured at the start of the experimental period, after two weeks, using a digital balance. These weights were determined at the same time in the morning. The positive control and experimental animals were observed for signs of abnormalities throughout the study. Our experiment data revealed a marked weight loss in all the diabetic groups except group 3, which also had a reduced final mean weight compared to the initial weight but not significant at $\mathrm{P}<0.05$ (Table II, Fig. I). However, a mean weight gain was observed in group 1, while the experiment lasted (Table II, Fig. I).

\begin{tabular}{|l|l|l|}
\hline GROUPS & INITIAL MEAN WEIGHT \pm SEM $(\mathrm{g})$ & FINAL WEIGHT \pm SEM $(\mathrm{g})$ \\
\hline 1 & $183.2 \pm 4.87$ & $193.2 \pm 2.08$ \\
\hline 2 & $188.4 \pm 2.16$ & $171.8 \pm 1.39^{*}$ \\
\hline 3 & $180 \pm 8.63$ & $166.2 \pm 5.82$ \\
\hline 4 & $172 \pm 5.32$ & $149.4 \pm 10.12^{*}$ \\
\hline 5 & $179 \pm 4.04$ & $144.2 \pm 3.51^{*}$ \\
\hline
\end{tabular}


Table III: Shows the mean \pm SEM of the initial and final weight of animals in each group. $*$ denotes the level of the significance $@ \mathbf{P}<\mathbf{0 . 0 5}$.

\section{BODY WEIGHT}

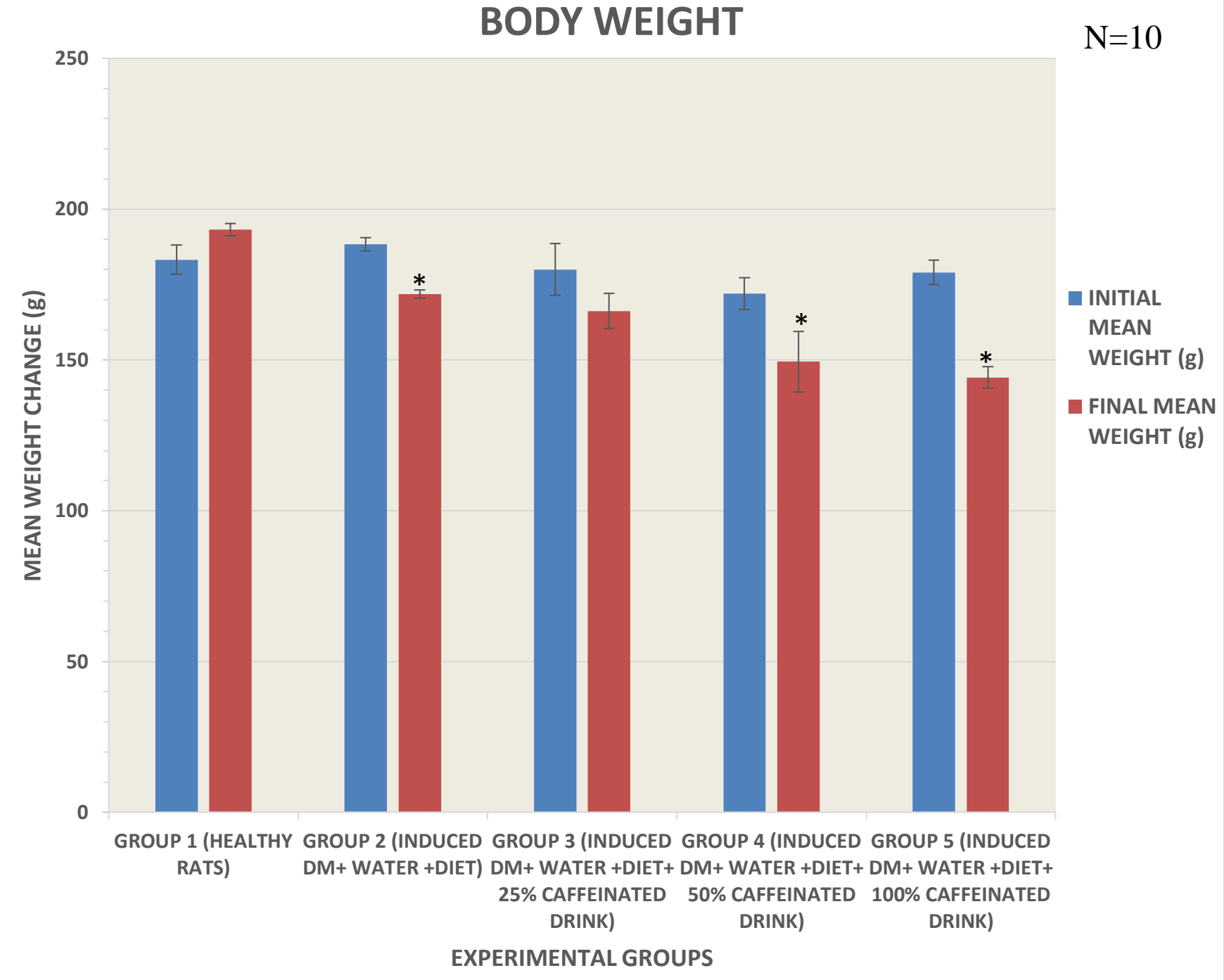

Fig. I Shows the mean \pm SEM of the initial and final mean weight in each group before and after the two (2) weeks experiment. * denotes the level of the significance @ $\mathrm{P}<0.05, \mathrm{~N}$ represents the total number of animals in each group, which is 10 .

\section{Lipi Profile}

Lipid profile, specifically Total cholesterol, Triglycerides, and LDL-Cholesterol level increased remarkably in group 2- Diabetic control group compared to the negative control (Table IV, Fig. II). However, HDL-Cholesterol significantly reduced in group 2, $3 \& 4$ compared to the negative control (Table IV, Fig. II). Similarly, in group 3 and group 4, Triglycerides and LDL-Cholesterol serum level were significantly increased compared to negative and positive controls (Table IV\& V, Fig. II). Also, HDL-cholesterol was significantly elevated in group 3 and 4 and 5 compared to group 2 (Table V, Fig. II). On the other hand, Total cholesterol level of group 3 and 4 was in equilibrium with group 1(Table IV, Fig. II).

Furthermore, all lipid profile measured in group 5 were in equilibrium with group 1- negative control, except HDLcholesterol, which increased significantly compared to group 1 (Table IV, Fig. II). 


\begin{tabular}{|l|l|l|l|l|l|}
\hline GROUP & $\begin{array}{l}\text { TOTAL } \\
\text { CHOLESTEROL } \pm \\
\text { SEM }(\mathbf{m m o l} / \mathbf{L})\end{array}$ & $\begin{array}{l}\text { TRIGLYCERIDES } \pm \\
\text { SEM }(\mathbf{m m o l} / \mathbf{L})\end{array}$ & $\begin{array}{l}\text { HDL- } \\
\text { CHOLESTEROL } \pm \text { SE } \\
\text { M }(\mathbf{m m o l} / \mathbf{L})\end{array}$ & $\begin{array}{l}\text { LDL- } \\
\text { CHOLESTE } \\
\text { ROL } \pm \text { SEM } \\
(\mathbf{m m o l} / \mathbf{L})\end{array}$ & $\begin{array}{l}\text { GLUCOSE } \\
\text { MEAN } \pm \text { SEM } \\
(\mathbf{m m o l} / \mathbf{L})\end{array}$ \\
\hline 1 & $2.30 \pm 0.78$ & $0.42 \pm 0.10$ & $1.64 \pm 0.12$ & $0.51 \pm 0.11$ & $5.58 \pm 0.13$ \\
\hline 2 & $3.80 \pm 0.20^{*}$ & $1.95 \pm 0.25^{*}$ & $0.60 \pm 0.10^{*}$ & $2.33 \pm 0.24^{*}$ & $16.86 \pm 0.19^{*}$ \\
\hline 3 & $2.87 \pm 0.15$ & $1.24 \pm 0.06^{*}$ & $0.86 \pm 0.07^{*}$ & $1.46 \pm 0.14^{*}$ & $17.55 \pm 0.04^{*}$ \\
\hline 4 & $2.79 \pm 0.89$ & $0.79 \pm 0.11^{*}$ & $1.40 \pm 0.06^{*}$ & $1.03 \pm 0.12^{*}$ & $15.30 \pm 0.46^{*}$ \\
\hline 5 & $2.39 \pm 0.91$ & $0.37 \pm 0.13$ & $1.97 \pm 0.11^{*}$ & $0.36 \pm 0.60$ & $16.40 \pm 0.17^{*}$ \\
\hline
\end{tabular}

Table IV: Shows comparison of the mean \pm SEM of Lipid Profile (Total cholesterol (TC), High-Density lipoprotein cholesterol (HDL-C), Triglyceride (TG), and Low-Density Lipoprotein cholesterol (LDL) of group 1 with group 2 , group 3 , group 4 and group 5. * denotes the level of the significance $@ P<0.05$.

\begin{tabular}{|l|l|l|l|l|l|}
\hline GROUP & $\begin{array}{l}\text { TOTAL } \\
\text { CHOLESTEROL } \pm \\
\text { SEM }(\mathbf{m m o l} / \mathbf{L})\end{array}$ & $\begin{array}{l}\text { TRIGLYCERIDES } \pm \\
\text { SEM }(\mathbf{m m o l} / \mathbf{L})\end{array}$ & $\begin{array}{l}\text { HDL- } \\
\text { CHOLESTEROL } \pm \\
\text { SEM }(\mathbf{m m o l} / \mathbf{L})\end{array}$ & $\begin{array}{l}\text { LDL- } \\
\text { CHOLESTE } \\
\text { ROL } \pm \text { SEM } \\
(\mathbf{m m o l} / \mathbf{L})\end{array}$ & $\begin{array}{l}\text { GLUCOSE } \\
\text { MEAN } \pm \text { SEM } \\
(\mathbf{m m o l} / \mathbf{L})\end{array}$ \\
\hline 2 & $3.80 \pm 0.20$ & $1.95 \pm 0.25$ & $0.60 \pm 0.10$ & $2.33 \pm 0.24$ & $16.86 \pm 0.19$ \\
\hline 3 & $2.87 \pm 0.15^{*}$ & $1.24 \pm 0.06^{*}$ & $0.86 \pm 0.07^{*}$ & $1.46 \pm 0.14^{*}$ & $17.55 \pm 0.04$ \\
\hline 4 & $2.79 \pm 0.89$ & $0.79 \pm 0.11^{*}$ & $1.40 \pm 0.06^{*}$ & $1.03 \pm 0.12^{*}$ & $15.30 \pm 0.46$ \\
\hline 5 & $2.39 \pm 0.91^{*}$ & $0.37 \pm 0.13^{*}$ & $1.97 \pm 0.11^{*}$ & $0.36 \pm 0.60^{*}$ & $16.40 \pm 0.17$ \\
\hline
\end{tabular}

Table V: Shows comparison of the mean \pm SEM of Lipid Profile (Total cholesterol (TC), High-Density lipoprotein cholesterol (HDL-C), Triglyceride (TG), and Low-Density Lipoprotein cholesterol (LDL) of group 2 with group 3 , group 4 and group 5. * denotes the level of the significance $@ P<0.05$. 


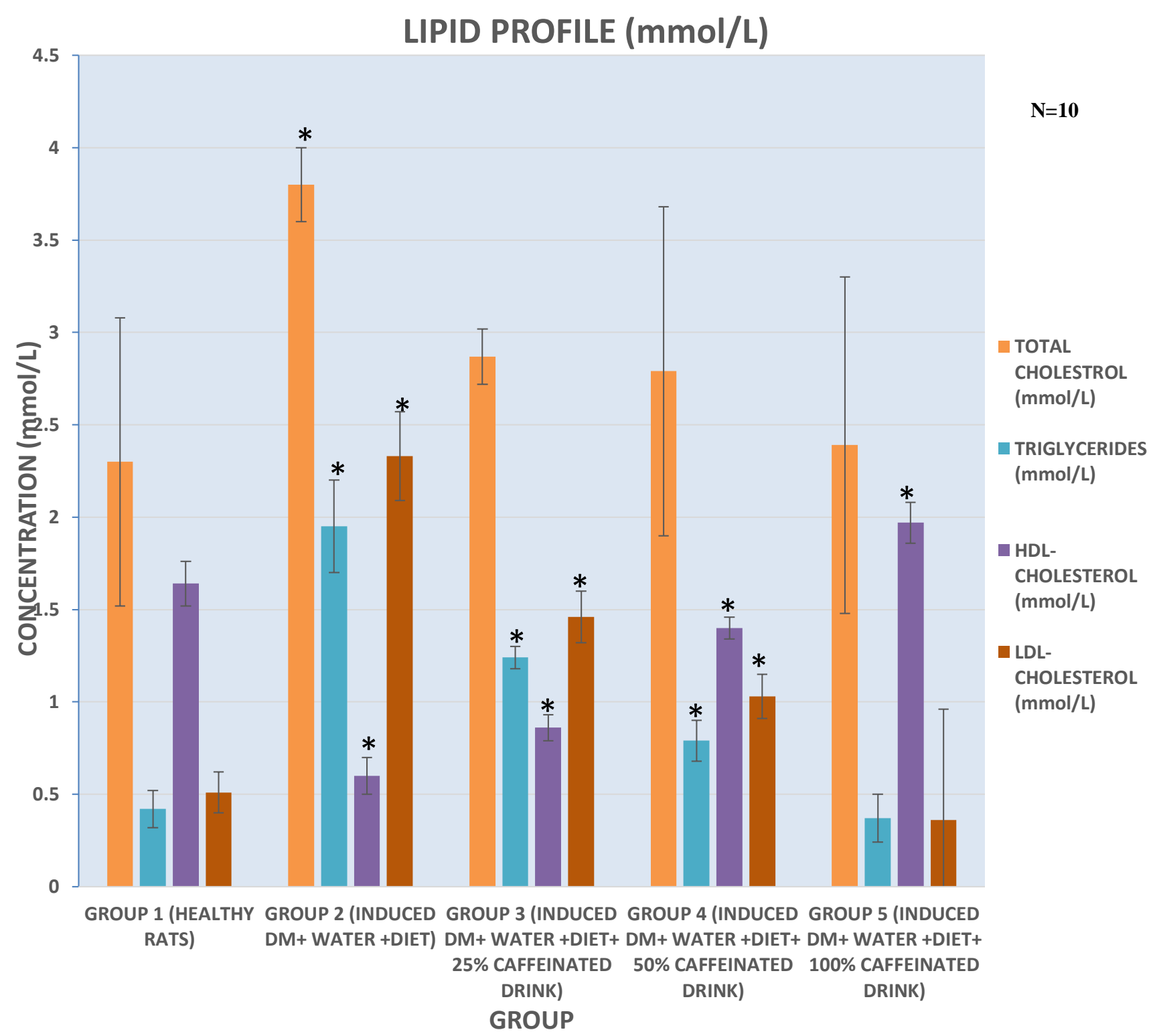

Fig. II: Shows the comparison of the Lipid Profile (Total cholesterol (TC), High-Density lipoprotein cholesterol (HDL-C), Triglyceride (TG), and Low-Density Lipoprotein cholesterol (LDL) between group 1 and group 2, group 3 , group 4 and group $5 .{ }^{*}$ denotes the level of the significance @ $\mathrm{P}<0.05, \mathrm{~N}$ represents the total number of animals in each group, which is 10 .

\section{Discussion:-}

In our study, there was a gradual reduction in the average body weight level in all the three experimental test groups that received relative percentages of caffeinated drink when the initial weights were compared to their final weight as shown in Table III and Fig I. The reduction in the final body weights of the experimental test groups can be attributed to the tendency of caffeine ability to promote sustained energy consumption or expenditure which was supported by the work of Liu et al., 2013. In Liu et al., 2013, they provided pieces of evidence that caffeine and ephedrine are active bodyweight loss agent and also help in the reduction of body fat mass.

Our present study revealed that total cholesterol, TG, and LDL were significantly elevated in the diabetic control group while HDL level remarkably decreased (Table IV, Fig. II). The administration of caffeinated drink for two 
weeks resulted in the reduction of serum level of total cholesterol, TG, and LDL to equilibrium with the negative control with a significant increase in HDL level (Table IV, Fig. II).

Diabetes mellitus is associated with hyperlipidemia with profound alteration in the concentration and composition of lipid (Odetola et al., 2006). The marked hyperlipidemia that characterized the diabetic group could be as a result of the change in the regulation of hormone-sensitive lipase activities caused by insulin deficiency, mediated by alloxan induction of diabetes in the experimental rats (Al-Shamaony et al., 1994). Also, alloxan significantly increases total cholesterol, triglycerides, LDL, VLDL, and A1C levels (Pari and Letha, 2005). The abnormally high concentration of serum lipid profile in alloxan-induced diabetes is primarily due to a rise in the mobilization of free fatty acids from the peripheral fat depots as a result of inhibition of hormone-sensitive lipase by insulin (Pari and Letha, 2005). As observed in this study, serum total cholesterol level of group $3,4, \& 5$ show no statistical significances at $\mathrm{P}<$ 0.05 compared to group $1 \& 2$ (Table IV \& V, Fig. II)., although, total cholesterol levels of group 3, 4, and 5 were low compared to group 2. In the case of the LDL-cholesterol level, statistical significance was seen in group 3, 4 and 5 when compared to group 2 (Table IV, Fig V) at $\mathrm{P}<0.05$, even though group 5 which has the least value is at equilibrium with group 1 LDL-cholesterol level (Table IV \& V, Fig. II). Furthermore, serum triglycerides level was remarkably elevated in group 3 and 4 compared to group 1 but significantly reduced when compared to diabetic control- group 2 (Table IV \& V, Fig. II. The serum triglycerides level of group 5 decreased to balance with group 1 (negative control) triglycerides level (Table IV, Fig. II). Hence, the serum level of TC, TG, and LDL-cholesterol reduced significantly, whereas, the serum HDL-cholesterol level increased remarkably at $\mathrm{P}<0.05$ when group 3, 4, and 5 were compared to group 2 (Table IV \& V, Fig. II). Lastly, the group 5 HDL-cholesterol level was highly elevated compared to the group 1 HDL-cholesterol level (Table IV, Fig. II). Consistent with our findings is the report of Yukawa et al. 2004 on the effect of the caffeine content of coffee on lipid profile (Yukawa et al., 2004). The caffeine content of the drink administered to animals in the experimental groups range from $100-306 \mathrm{mg} / 32 \mathrm{fl}$, which is equal to the amount of caffeine derived from daily consumption of 2 cups of coffee (Frary et al., 2005). Therefore, the caffeinated drink had hypolipidemic potential, and this may be an indication of progressive metabolic control of caffeinated beverage on the mechanism involved in the elimination of the lipids from the body.

After the administration of the relative percentage of caffeinated drink to the three experimental groups, the rats were seen to be recovering from the illness. This observation shows that caffeinated drink may reverse the risk/ and complication of diabetes. Our findings are in line with lines of works, which found that frequent consumption of caffeinated coffee may reduce the risk of diabetes mellitus and liver cancer (Van Dam, 2008) as well as ameliorate diabetic-induced oxidative stress damage (Ogundiran et al., 2019). Although we recorded death of the experimental rats in the diabetes-induced groups during the experiment, this is an event consistent with the report from Lennon's study that, severe diabetic-induced oxidative stress can cause cellular injury and eventually death (Lennon et al., 1991).

\section{Conclusion:-}

Our study demonstrates that caffeinated drinks were found to significantly restore the status of the lipid profile to near normal range in alloxan-induced diabetic rats. It was also found to be highly effective in managing the complications associated with diabetes mellitus, such as hyperlipidemia and prevents the defects in lipids metabolism.

The effect of caffeinated drink increases as the concentration of the dose increases but preferably $100 \%$ caffeinated drink is much effective against this condition as the effectiveness decreases when the concentration reduces to $50 \%$ and $25 \%$ respectively. Therefore, caffeinated drink shows therapeutic promise as a protective agent against the development and progression of atherosclerosis and possible related cardiovascular complications in diabetes mellitus.

\section{Conflict Of Interest: None}




\section{Reference:-}

1. Al-Shamaony, L., Al-Khazraji, S. M. and Twaij, H. A. (1994). Hypoglycaemic effect of Artemisia herbaalba. II. Effect of a valuable extract on some blood parameters in diabetic animals. J. Ethnopharmacol., 43:167-171.

2. Chattopadhy, R. and Bandyopadhyay, M. (2005). Effects of Azadirachtaindica leaf extract on serum lipid profile changes in normal and streptozotocin induced diabetic rats. Afr. J. Biomed. Res., 8: 101-104.

3. Das, S. and Mohan, V. (2003). Disorders of lipid metabolism. In: Shah SN Ed. API text Book of medicine, $75^{\text {th }}$ edition association of physician of India, Mumbai, 250-258.

4. Davis, J. K., and J. M. Green. (2009). Caffeine and anaerobic performance: ergogenic value and mechanisms of action. Sports Medicine. 39:813-832.

5. Frary, C. D., Johnson, R. K. and Wang, M. Q. (2005). Food sources and intakes of caffeine in the diets of persons in the United States. J. Am. Diet. Assoc., 105:110-113.

6. Gandhi, H. (2001). Diabetes and coronary artery disease: importance of risk factors: cardiol-Today,1: 31-34.

7. Graham, T. E. (2001). Caffeine and exercise. Metabolism, endurance and performance. Sports Medicine. 31:785-807.

8. Howard, B.V. (1987). Lipoprotein metabolism in diabetes mellitus. J. Lipid Res., 28: 613-614.

9. Kahn, R. (1994). Banting Lecture: Insulin action, diabetogenes and cause of type II diabetes. Diabetes, 43: 1046-1084.

10. Lennon, S. V., Martin, S. J. and Cotter, T. G. (1991). Dose dependent induction of apoptosis in human tumour cell lines by widely diverging stimuli. Cell Prolif., 24: 203-214.

11. Liu, A. G., Smith, S. R., Fujioka, K. and Greenway, F. L. (2013). The Effect of Leptin, Caffeine/Ephedrine and their Combination upon Visceral Fat Mass and Weight Loss. Obesity, 21: 1991-1996.

12. Manninen, V., Tenkanen, L. and Koskinien, P. (1992). Joint effects of serum triglycerides and LDL cholesterol and HDL cholesterol concentrations on coronary heart disease risk in the Helsinki heart study: implications for treatment. Circulation, 85: 37-45.

13. Odetola, A. A., Akinloye, O., Egunjobi, C., Adekunle, W. A. and Ayoola, A. O. (2006). Possible antidiabetic and antihyperlipidaemic effect of fermented ParkiaBiglobosa (JACQ) extract in alloxan-induced diabetic rats. Clin. Exp. Pharmacol. Physiol., 33:808-812.

14. Ogundiran, S. M., Oladapo, A.A. and Akinola, F.F. (2019). Effects Of Caffeinated Drink On Antioxidant Status In Alloxan-Induced Diabetic Male Albino Rats" IOSR Journal of Environmental Science, Toxicology and Food Technology (IOSR-JESTFT) 13.8: 19-27.

15. Pari, L. and Latha, M. (2005). Antidiabetic effect of Scopariadulcis: Effect onlipid peroxidation in streptozotocin diabetes. Gen. Physiol. Biophys., 24:13-26.

16. Szkudelski, T. (2001). The mechanism of alloxan and streptozotocin action in $\beta$-cells of the rat pancreas. Physiol. res., 50: 537-546

17. Van Dam, R.M. (2008). Coffee consumption and risk of type 2 diabetes, cardiovascular diseases and cancer. Appl. Physiol. Nut. Met., 33(6): 1269-1283.

18. Vats, V., Grover, K. and Rathi, S. (2002). Evaluation of antihyperglycaemic and hypoglycaemic effect of Trigonellafoenum-graecumLinn.,ocimum sanctum Linn and Pterocarpus marsupium Linn in normal and alloxanised diabetic rats. J. Ethnopharmacol., 79: 95-100.

19. Yukawa, G.S., Mune, M., Otani, H., Tone, Y., Liang, X.M. and Iwahashi, H. (2004). Effects of coffee consumption on oxidative susceptibility of Low-Density Lipoproteins and serum lipid levels in humans. Biochem., 69(1): 70-74. 